\title{
USE OF GAMIFICATION IN HUMAN RESOURCE MANAGEMENT: IMPACT ON ENGAGEMENT AND SATISFACTION
}

\author{
Daiga Ërgle ${ }^{1}$, Iveta Ludviga ${ }^{2}$ \\ ${ }^{1}$ University of Latvia, Riga, Latvia \\ ${ }^{2}$ Business Department, RISEBA University of Business, Arts and Technology, Meza 3, Riga, Latvia \\ E-mails: 'Daiga.Ergle@4finance.com (corresponding author); ${ }^{2}$ iveta.ludviga@riseba.lv
}

\begin{abstract}
The use of games, also called gamification, is innovative an approach in contemporary human resource management. The aim of this research is to assess whether gamification, if used in HR processes, can increase engagement and job satisfaction among employees, as well as to identify which HR processes respond better to gamification. Using data from CAWI interviews $(n=620)$ and Structural Equation Modelling (PLS-SEM) method with smartPLS software, the researchers found a significant positive impact of gamification on employee job satisfaction, however, no impact on engagement. Teambuilding and internal communication were identified as HR processes which better respond to gamification and recommendations for HR managers provided.
\end{abstract}

Keywords: gamification, human resource management, engagement, job satisfaction, structural equation modelling.

JEL Classification: M50, M54, M59.

\section{Introduction}

Gamification refers to the use of games and gamerelated components outside the traditional playground with a serious purpose within organisations or training institutions (Gimson, 2012; Brownhill, 2013) with an aim to make everyday duties more attractive and pleasant (Sarangi \& Shan, 2015). In the past few years, gamification has emerged as a trend within the business and marketing sectors and has recently grabbed the attention of academics, educators and practitioners (Seaborn \& Fels, 2015). Researchers and practitioners consider that gamification can be used in any process which involves employees (Callan, Bauer, \& Landers, 2015).

Gamification is not simply playing games. According to Kim (2015), games create the imaginative world, which differs from reality, however, gamification augments reality with the elements of a game. Elements of a game beyond traditional format of the game motivate people to act and create fun, thus increase participant's engagement and motivation (Kapp, 2014; Zichermann \& Cunningham, 2011). Mollick and Rothbard (2014) view gamification from the perspective of employer - as a tool to engage employees in some kind of competition and thus contributing to the achievement of organisational goals.
Research by American Society for Training \& Development in 2013 found that 23\% of organisations use gamification in training and development process and $99 \%$ of them are sure that this method is effective. Moreover, 4 out of 10 organisations who do not use gamification stated that they plan to start using it next year (Oakes, 2014).

Currently, the most common applications of gamification are in the areas of employee performance, innovation management, education, personal development and customer engagement. Still, the trend of gamification, as every technological emerging trend, goes through a cycle of success and failure. According to Gartner's hype cycle, gamification is starting to go through a 'trough of disillusionment'. This means that the hype of the trend is over and due to some failures of gamification there is more awareness of the advantages and disadvantages of this technology. People recognize that gamification cannot solve every problem, that there are limits to the use of gamification and that improvement is still necessary (Gartner, 2015). According to Gartner (2015) gamification, applied with correct game design principles, can and will have a significant impact in many domains, and in some fields, the use of game mechanics will have a transformational impact. However, a lot needs to be done. Therefore, in this stage, there is a pressing need for empirical 
studies to validate what effect, and the extent of the effect, gamification features have on participants' performance and enjoyment as well as to identify best practices (Seaborn \& Fels, 2015).

Despite the widespread use of gamification, the research on effects of gamification is still scarce and there is lack of empirical evidence about the results. It is not clear should organisations really use gamification in HR or it is just the latest management fad. The aim of this research is to find empirical evidence about the effect of the use of gamification in HR processes on employee engagement and job satisfaction. Moreover, the paper assesses the level of the use of gamification in different HR processes in Latvian organisations as well as identifies which generations accept gamification better.

The paper is structured as follows: in theoretical part first gamification is defined, then its use in human resource processes discussed and hypotheses developed. Further research methodlogy is described, and findings presented.

\section{Gamification defined}

Although gamification is a popular word nowadays, there are quite a few definitions used $(\mathrm{Xu}$, 2011) and quite some discussion on what the right definition is. This might be because theoretical foundations are inconsistently referenced and interpreted. Also, there is a gap between theory and practice - where theory is empirically unexamined and applied work lacks reference to theory (Seaborn \& Fels, 2015, p. 27).

According to Seaborn \& Fels (2015) gamification has been largely, though inconsistently, referred to as the selective incorporation of game elements into an interactive system without a fully-fledged game as the product. Gamification is also described as the use of game design elements in non-game context (Deterding, Dixon, Khalad, \& Nacke, 2011). An important remark, however, is the high level of subjectivity in identifying "gamification". The concept of 'game design elements' and 'non-game context' are both arguable since there is no universal list of game elements (Werback, 2014). Therefore, it is not possible to determine whether a given empirical system is "a gamified application" or "a game" without taking recourse to either the designers' intentions or the user experiences and enactments (Deterding et al., 2011, 2012). To overcome this problem Werbach (2014) redefines gamification as 'a process of making activities more game-like'. Within this definition it is not necessary to define a point where the designed system crosses over in gamification as in the definition of Deterding. Huatari and Hamari (2012) also don't agree with the definition of Deterding because they believe the focus should be more on the user's experience. Hence, they define gamification as "a process of enhancing a service with affordances for game full experiences in order to support user's overall value creation" (Huatari \& Hamari, 2012, p. 19). Nevertheless, the definition of Deterding is the most widespread; therefore, for the purposes of this research Deterding's definition of gamification is applied: 'the use of game design elements in non-game context' (Deterding et al., 2011).

\subsection{Use of gamification in $H R$}

Gamification can be used in any sphere of business (Saran, 2013), including human resource management. Since human capital is the intangible asset that primarily account for the performance of the firms (Mollick \& Rothbard, 2014), companies are looking for new solutions to engage employees and ensure that they work with greater enthusiasm and contribute to the achievement of business goals. During the last 5 years or so, interest of practitioners has spread to use game applications into different HR processes. Recently, more and more companies are using different gaming technologies, thereby involving employees and changing their behaviour. HR function uses different gamification tools to improve induction processes, employee training and development, team-building, talent management processes, and performance management (Roberts, 2014). Gamification adds joy to everyday duties which otherwise can be quite boring (Sarangi \& Shan, 2015). Researchers and practitioners consider that gamification can be used practically in any process which involves employees (Callan et al., 2015).

Meister (2015) states that gamification includes $75 \%$ psychology and $25 \%$ technology and can be applied to any process in real organisation starting with recruitment and ending with training and development. From the psychological perspective, gamification increases employee engagement through inner motivation, aim setting and experience of competition (DuVernet \& Popp, 2014). Involvement in games can change employee behaviour, allow them to view their organisation from the different perspective (Hughes \& Mccoy, 2015).

In order to find evidence of the effectiveness of the use of gamification in HR processes it is 
important to understand how to measure HR processes and management, therefore further employee engagement as the outcome of efficient HR management is discussed.

\subsection{Engaged employees as a result of effective management}

Researchers and practitioners agree that engaged employees are better performers. For example, Mihalicz found that productivity of engaged employees is $21 \%$ higher, profitability $22 \%$ higher and customer ratings are 10\% higher (Mihalicz, 2018). Moreover, Harter and Adkins (2015) research found that managers account for $70 \%$ of the variance in employee engagement. Consequently, employee engagement is frequently regarded as one of the most significant measurements for management efficiency (Ergle, 2015).

Engaged employees as those who are actively involved in and enthusiastic about their work and organisation (SHRM, 2014). It is managers job to create and foster employee engagement (Harter \& Adkins, 2015).

Robinson defines engagement as a 'positive attitude towards the organisation and its values' (Robbins \& Coulter, 1999). Similarly, engagement is defined as "a positive, fulfilling, work-related state of mind" (Schaufeli, Bakker, \& Salanova, 2006). Engagement happens when "organisation members harness their full selves in active, complete work role performances by driving personal energy into physical, cognitive and emotional labours" (Rich, Lepine, \& Crawford, 2010).

Engagement is closely connected to job satisfaction. Both constructs are important for HR but are not the same (ADP Research Institute, 2012). Researchers consider job satisfaction as part of, or component of engagement (Morgan, 2015) while others state that satisfaction is antecedent of engagement (Markos \& Sridevi, 2010). According to recent research in Latvia satisfaction appeared to be a component of engagement (Ludviga \& Kalvina, 2016), therefore both constructs are selected as outcome variables in this research.

\subsection{Linking gamification to employee engagement}

Businesses currently are looking for new innovative ways to engage employees and gamification is one such option. Researchers have found that playful activities and well-developed gamification as part of HR process can decrease employee burnout (Sarangi \& Shan, 2015) as well as can have far-reaching benefits, for example, increase in retention and satisfaction, improved communication, employees will become open to taking risks and more creative (Smith \& Meyerson, 2015).

Gamification was found to be an effective component of learning and development process (Whyte, 2016), it can improve organisational culture, reveal talents, foster innovation and engagement (Kumar \& Raghavendran, 2015).

In line with the theory the following hypotheses are formulated:

H1: Use of Gamification in Human Resource Management processes has a positive impact on Employee Engagement level;

H2: Use of Gamification in Human Resource Management processes has a positive impact on Employee Satisfaction level.

\subsection{Gamification and structure of the workforce}

Use of gamification is promoted also due to generational shift since forward-thinking companies are adapting themselves to the demands of new generation by embracing the process of gamification (Savitz, 2012).

Millennials (born between early 1980ies and 2000) and Generation Z (born between 1996 and 2010) has entered the labour market and these people are used to spend part of their free time playing digital games (Kastner, 2013), so it can be expected that gamification will engage them in their working life. The popularity of video games is growing, and video game industry revenue has surpassed the Hollywood. Looking at the statistics, the average age of the player is 37 years (Brownhill, 2013). Researchers have found that engaging millennials include co-creation of experiences that may also take place in or be facilitated in the virtual world (Skinner, Sarpong, \& White, 2018).

Data shows that there is a significant relationship between the following: the more people play games outside of working hours, the greater the likelihood that they engage in games while work (Mollick \& Rothbard, 2014).

In line with the theory the following hypotheses are formulated:

H3: Younger employees (millennials \& generation Z) respond better to gamified HRM processes in terms of engagement

H4: Younger employees (millennials \& generation Z) respond better to gamified HRM processes in terms of satisfaction 


\section{Methodology}

The quantitative research design was chosen to prove the hypotheses. Data was gathered in Latvia using CAWI interviews: number of respondents 620 , general pool of respondents - individuals employed in Riga and Riga region, age group between 18 and 65 years old.

The structured questionnaire was designed according to the research model. The model was designed with two dependent variables: engagement and satisfaction. Four factors were designed as independent variables which impact engagement and satisfaction: job itself, management, colleagues and character of the employee. Respondents were asked to state the level of their agreement with the statement. All variables were measured using 10-point Likert type scale, where 1 was assigned to "completely disagree" and 10 to "completely agree".

The survey was prepared in Latvian language and included demographic variables like respondents' gender, age and whether they are currently employed. Only those who approved their employment were asked to continue. Further, information about the industry sector, the size and age of the organisation were asked. Further the constructs, their coding, number of corresponding statements and samples are described. Engagement (ENG) was measured with 7 statements and sample statement is "I invest more effort in my job than my direct responsibilities require". Satisfaction was measured with 5 statements, including overall satisfaction with the level of stress, payment, environment, and workload. Similarly, colleagues, management and job itself was measured with 6, 5 and 5 statements respectively. Since it might be assumed that only employees with positive character respond positively to use of gamification in HR, the character traits of the respondent were measured with 7 statements and sample statements are "I am satisfied with my life" and "I am an optimistic person who usually expects positive outcomes".

Use of gamification in HR functions was measured with yes/no type question where "yes" was coded as 1 and "no" as 2 . Respondents were asked to identify whether gamification is being used in their organisations in recruitment and onboarding; performance management; reward and recognition; learning and development; internal communication; teambuilding and other. Questionnaire scales, coding and number of statements per scale and internal consistency reliability of the scales (Cronbach's Alpha) are seen in Table 1.
Table 1. Internal consistency measures of the construct scales

\begin{tabular}{|l|c|c|}
\hline $\begin{array}{c}\text { Variables and their } \\
\text { codes }\end{array}$ & $\begin{array}{c}\text { No. of } \\
\text { items }\end{array}$ & $\begin{array}{c}\text { Cronbach's } \\
\text { Alpha }\end{array}$ \\
\hline Character (CAR) & 7 & 0.847 \\
\hline Colleagues (COL) & 6 & 0.914 \\
\hline Job (JOB) & 5 & 0.860 \\
\hline Management (MNG) & 5 & 0.932 \\
\hline Satisfaction (SAT) & 5 & 0.852 \\
\hline Engagement (ENG) & 7 & 0.898 \\
\hline
\end{tabular}

\section{Analysis and Findings}

Data was analysed with SPSS and smartPLS software. Data available in Table 2 and Figure 1 show that gamification in Latvian organisations is more used for learning and development purposes, followed by internal communication and teambuilding. Since us of gamification in HR processes was yes/no type question, Figure 1 presents the percentage of respondents who answered "yes" meaning that gamification is used in the respective HR process in their organisation.

Table 2. Descriptive statistics of the construct scales $(n=620)$

\begin{tabular}{|l|c|c|}
\hline \multicolumn{1}{|c|}{ Variables } & $\begin{array}{c}\text { Mean } \\
\text { values }\end{array}$ & $\begin{array}{c}\text { Standard } \\
\text { deviation }\end{array}$ \\
\hline Character (CAR) & 7.05 & 1.52 \\
\hline Colleagues (COL) & 6.79 & 1.81 \\
\hline Job (JOB) & 7.24 & 1.75 \\
\hline Management (MNG) & 6.85 & 2.16 \\
\hline Satisfaction (SAT) & 6.67 & 1.91 \\
\hline Engagement (ENG) & 6.80 & 1.82 \\
\hline Use of gamification in HR process: \\
\hline $\begin{array}{l}\text { recruitment and onboarding } \\
\text { (HR_RO) }\end{array}$ & 1.79 & 0.40 \\
\hline $\begin{array}{l}\text { performance management } \\
\text { (HR_PM) }\end{array}$ & 1.73 & 0.45 \\
\hline $\begin{array}{l}\text { rewards and recognition } \\
\text { (HR_RR) }\end{array}$ & 1.68 & 0.47 \\
\hline $\begin{array}{l}\text { learning and development } \\
\text { (HR_LD) }\end{array}$ & 1.63 & 0.48 \\
\hline $\begin{array}{l}\text { Internal communication } \\
\text { (HR_IC) }\end{array}$ & 1.64 & 0.48 \\
\hline teambuilding (HR_TB) & 1.66 & 0.47 \\
\hline Other (HR_OTHER) & 1.80 & 0.40 \\
\hline
\end{tabular}

To evaluate whether the use of gamification in HR processes creates differences in satisfaction and engagement, nonparametric test Mann-Whitney Test for mean differences is used. Learning 
and development appeared to be the HR process in which gamification is used more than in other processes (see Figure 1).

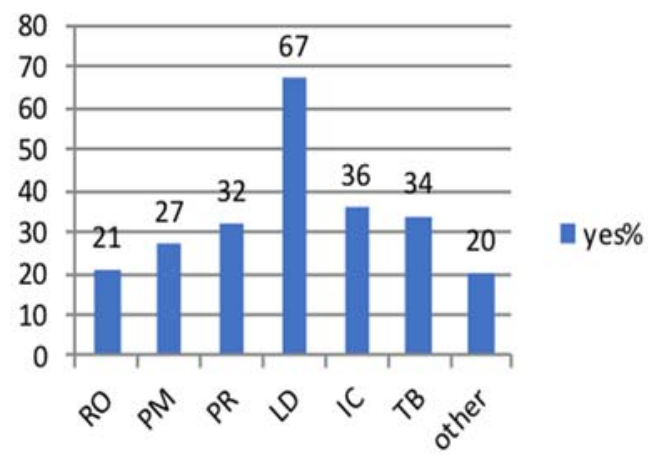

Figure 1. Use of gamification in HR processes in Latvian organisations ("yes" answers in \%)

Use of gamification in all HR processes creates statistically significant differences in engagement and satisfaction of the respondents $(\mathrm{p}<0$, 05) However, differences in recruitment and onboarding (RO) process are statistically significant only at $90 \%$ confidence $(\mathrm{p}<0.1)$. Figures 2 and 3 below present the differences in engagement and satisfaction between respondents who claim that gamification is used and those who claim that it is not used in HR processes.

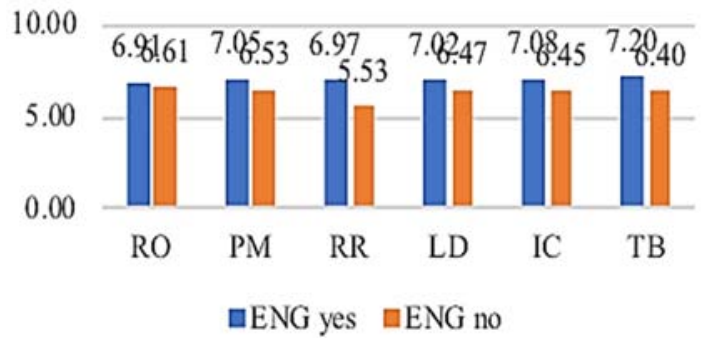

Figure 2. Engagement when gamification is used or not used in HR processes (mean values)

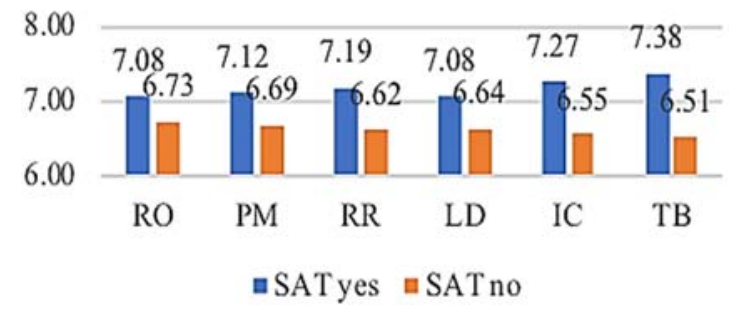

Figure 3. Satisfaction when gamification is used or not used in HR processes (mean values)

This conclusion might lead to the acceptance of H1 (Use of Gamification in Human Resource Management processes positively influence Employee Engagement level) and H2 (Use of Gamifi- cation in Human Resource Management processes positively influence Employee Satisfaction level); however, the test for mean differences does not indicate anything about the influence. There might be other factors, which are not included in the analysis which influences the level of engagement and satisfaction. Put it differently, organisations which use gamification in HR process are generally better in HR, they do the other entire thing better, they have more advanced HR function, therefore the level of satisfaction and engagement of their employees is generally higher.

\subsection{Structural Equation Modelling Results}

Further variance based Structural Equation Modelling (PLS-SEM) method was used to prove or reject the hypotheses since it is applicable for relatively small samples and when research area is relatively new (Ringle, Wende, \& Becker, 2014). Besides this technique allows exploring a larger number of relationships simultaneously (Hair \& Ringle, 2011). The statistical objective of PLSSEM is to maximize the explained variance of endogenous latent constructs (independent variables), or exogenous constructs (dependent variables), in this research satisfaction and engagement.

Before drawing any conclusion regarded relationships between constructs, the model reliability and validity were assessed with Smart PLS software and algorithms calculated (see Figure 4). The measurement model (outer model) showed that loadings of all manifest variables are above the minimum threshold value 0.708 . Thus, all the manifest variables exhibit outer loadings high enough and are a good measure of their latent variables.

Internal consistency reliability was assessed using Cronbach's alpha and composite reliability and average variance extracted (AVE). Cronbach's alpha coefficients for the model are all above 0.8 , thus the scales exhibit good internal consistency reliability (see Table 1).

Composite Reliability is an estimate of constructs ' internal consistency and should be above threshold level 0.7 . Composite reliability scores of the model are in between 0.88 and 0.95 , what is well above the minimums thus indicating sufficient reliability.

Convergent Validity of the reflective constructs is examined with average communality or AVE (average variance extracted). It should be at least higher than 50\%. All AVE scores are above 0.5 and thus are acceptable. 
Discriminant Validity represents the extent to which measures of a given construct differ from measure of other constructs in the same model. Heterotrait-Monotrait (HTMT) ratio of correlations is used to measure discriminant validity (Hair \& Ringle, 2011). HTMT is a ratio of the within construct correlations to the between construct correlations. All HTMT values should be lower than 0.85 for conceptually distinct constructs, such as work management perceptions and compensation, and lower than 0.9 for similar constructs. Since all values are lower than 0.85 thus the validity is confirmed. Besides Bias Corrected confidence intervals showed that neither the high nor the low confidence intervals include a value of 1 . Thus, the discriminant validity is demonstrated by the HTMT method.

Collinearity statistics revealed that all values are in between 1.408 and 4.306, thus they are less than 5 , thus indicating that collinearity is not a problem for the model.

As calculated by PLS algorithm, $\mathrm{R}^{2}$ values $\left(R^{2}\right.$ satisfaction $=0.423 ; R^{2}$ engagement $\left.=0.612\right)$, the model explains $42 \%$ of satisfaction and has moderate predicting capacity. The model explains $61 \%$ of engagement, thus showing moderate to high predicting capacity for this construct. Another measure which allows evaluating the goodness of fit of the model is PMS theta and values below 0.14 provide support for model fit (Becker, Ringle, \& Sarstedt, 2017). For the model presented in Figure 4 PMS theta $=0.018$, thus the fit of the model is good.
The higher-order model approach was used for gamification in HR processes - the higher-order component (GAM-HR) was introduced using repeated indicators approach. Reason for using higher-order model is, according to Becker, to reduce the number of inner model relationships (Becker et al., 2017). Due to measurement specifics, negative path coefficient shows the positive impact of the use of gamification in HR on engagement and satisfaction.

Bootstrapping results and path coefficients show that relationship between gamification and engagement (GAM_HR -> ENG path coefficient $-0.003 ; p=0.89$ ) is not significant, thus $\mathrm{H} 1$ should be rejected. Relationship between gamification and satisfaction (GAM_HR -> SAT path coefficient $-0.061 ; \mathrm{p}=0.069<0.1)$ is statistically significant at $90 \%$ confidence. Thus, H2 can be accepted.

Internal communication (IC) and team-building (TB) are HR processes which show a statistically significant impact on GAM-HR. Moreover, total indirect effect, which includes the effect of the manifest variable on the dependent variable through independent variables, of teambuilding (TB) on satisfaction is statistically significant: (HR_TB $\rightarrow$ SAT path coefficient -0.045; $\mathrm{p}=0.073<0.1$ ). This allows concluding that use of gamification in HR process teambuilding has a positive and statistically significant impact on employee satisfaction.

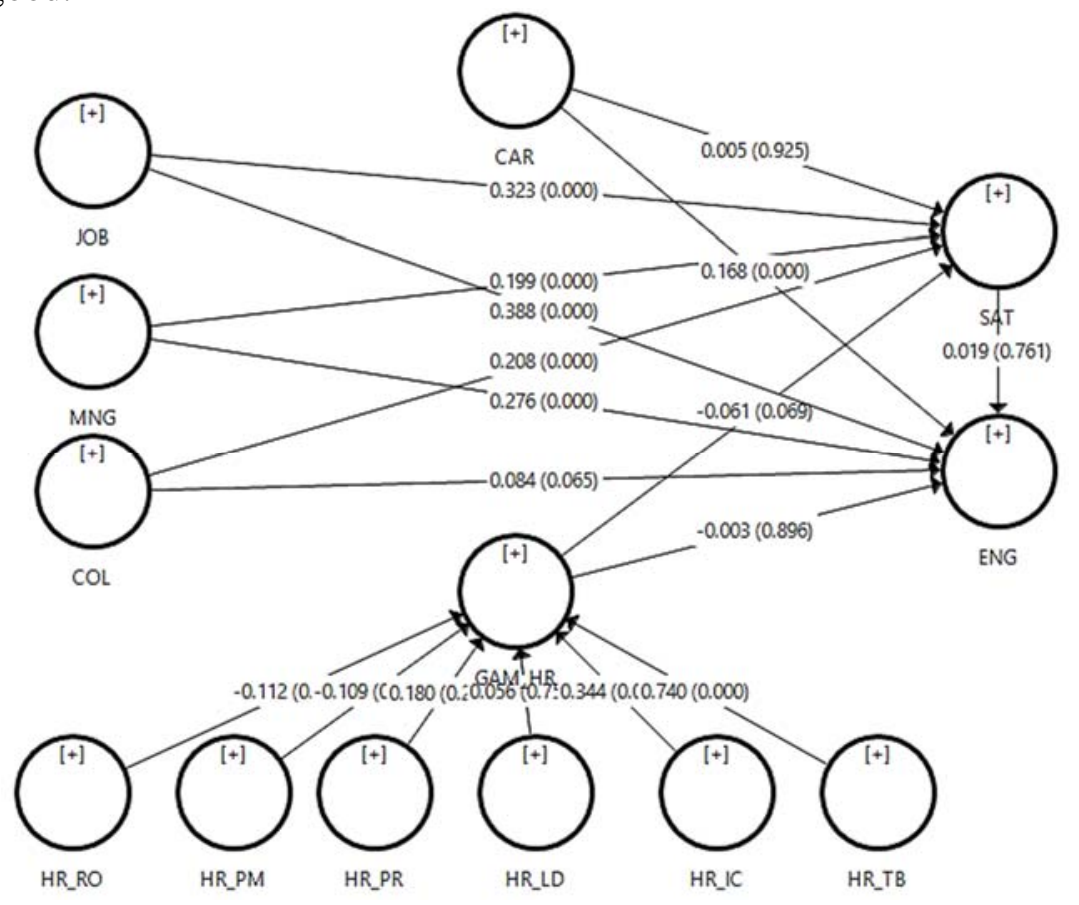

Figure 4. Model with Gamified HR processes (PLS algorithm) 


\subsection{Multigroup analysis by generations}

To draw conclusions regarding $\mathrm{H} 3$ and $\mathrm{H} 4$ multigroup analysis using age as grouping variable was performed. Respondent belonging to millennials and generation $Z(n=241)$ were compared with generations $X$ and Baby Boomers $(n=379)$.

Results show that path from GAM_HR$>$ SAT is stronger for older respondents and differences are statistically significant. For younger group relationship appeared to statistically insignificant (path coefficient $-0.01 ; \mathrm{p}=0.85$ ), however for the older group it was significant (path coefficient $-0.1 ; \mathrm{p}=0.023$ ). Moreover, differences between groups appeared to be statistically significant (path coefficient difference 0.09; $\mathrm{p}=0$, 09). Thus, H3 and H4 should be rejected. Interestingly, that the opposite appears to be true: older employees (generations X \& BB) respond better to gamified HRM processes in terms of satisfaction. This might be explained by the fact that a younger employee play games outside the job and therefore the use of gamification at work does not provide any additional satisfaction for them. Whereas older employees are not used to games, therefore gamification at work seem innovation and appears to be interesting for them.

The findings provided the following conclusions about the hypotheses:

H1: Use of Gamification in Human Resource Management processes has a positive impact on Employee Engagement level (rejected);

H2: Use of Gamification in Human Resource Management processes has a positive impact on Employee Satisfaction level (accepted);

H3: Younger employees (millennials \& generation Z) respond better to gamified HRM processes in terms of engagement (rejected);

H4: Younger employees (millennials \& generation Z) respond better to gamified HRM processes in terms of satisfaction (rejected).

\section{Discussion and Conclusions}

This research aimed to provide empirical evidence about the effect of the use of gamification in HR processes. The level of the use of gamification in different HR processes in Latvian organisations was evaluated and generational differences in respect to acceptance of gamification identified.

In Latvian organisations gamification is primarily used in learning and development process $-67 \%$ of respondents approved this. This finding is in line with DuVernet and Popp who identified that learning and development is one of the HR processes where gamification is frequently used. In all other HR processes use of gamification is below $36 \%$. Thus, it can be concluded that gamification is entering HR in Latvian organisations, however, not widely used yet.

Influence of gamified HR processes on employee engagement was not identified in Latvian organisations. This result contradicts findings by Jensen, who regarded gamification as next big hope in fostering employee engagement (Jensen, 2012) and Sarangi and Shan who have developed which demonstrates the impact of gamification on employee engagement (Sarangi \& Shan, 2015). The result of this research in Latvia might be explained by the fact that in Latvia Gamification is a very new phenomenon and not widely used, except learning and development process. Consequently, the impact on engagement is not felt yet. Other reason might be related to the complicity of this approach. Several authors have identified negative outcomes of gamification if not used correctly (e.g. Bogost, 2015). For example, Callan and colleagues stated the importance of fit between organisational aims and players

aims (Callan et al., 2015) and Kastner (2013) stressed that weak application of gamification can even hurt the reputation of the organisation.

The positive influence of the use of gamification in HR processes on satisfaction was found. Among HR processes which better respond to gamification appeared to be team-building and internal communication, moreover, team-building showed a significant indirect impact on satisfaction. The impact of learning and development, which was the most frequently gamified HR process in Latvian organisations, on job engagement and satisfaction, according to the analysis, appeared to be insignificant. Thus, the findings of this research lead to a recommendation $t$ Moreover, since older generation focus on team-building and internal communication.

An interesting finding is related to age - although it was hypothesised that younger generation responds better to use of gamification in HR, it appeared to be vice versa. The older generation (generations $\mathrm{X} \& \mathrm{BB}$ ) respond better to gamified HRM processes in terms of satisfaction.

Regarding managerial implications, managers should acknowledge the possibilities offered by the use of gamification in HR processes, especially it is recommended to use it for teambuilding purposes. Moreover, since older generation responds to gamification even more favour- 
ably than younger ones, it might be recommended to use gamification, especially with older employees.

However, gamification should be used carefully, and proper game design ensured. Since the purpose of this research was not related to the identification of effective game design and game content, this could be proposed as the subject of future research.

The findings should be considered in light of the research limitations. The electronic survey method was used, and it might be affected by common method bias. The second limitation is related to geographical coverage, data was gathered only in Latvia and this limits the generalizability of the findings. Moreover, the result was measured only as respondent's perception and the number of independent variables was limited. Further studies could be extended to other locations and include more manifest variables.

\section{Disclosure Statement}

Authors declare no competing financial, professional, or personal interests from other parties.

\section{References}

ADP Research Institute. (2012). Employee Satisfaction vs. Employee engagement: Are they the same things?, ADP inc.

Becker, J.-M., Ringle, C. M., \& Sarstedt, M. (2017). PLSSEM using SmartPLS 3 foundations. Hamburg, Germany: Northern Institute of Technology.

Bogost, I. (2015). Gamification is bullshit. In S. P. Walz \& S. Deterding (Eds.), The gameful world: Approaches, issues, applications (pp. 65-79). Cambridge: The MIT Press.

Brownhill, I. (2013). Does gaming have a role to play in employee engagement?. Strategic HR Review, 12(1), 5-8.

Callan, R. C., Bauer, K. N., \& Landers, R. N. (2015). How to avoid the dark side of gamification: Ten business scenarios and their unintended consequences. In T. Reiners \& L. C. Wood (Eds.), Gamification in Education and Business (pp. 553-568). New York: Springer International Publishing. https://doi.org/10.1007/978-3-319-10208-5_28

Deterding, S. (2012). Gamification: designing for motivation. Interactions, 16(4), 14-17. https://doi.org/10.1145/2212877.2212883

Deterding, S., Dixon, D., Khalad, R. \& Nacke, L. (2011). From game design elements to gamefulness: defining Gamification. In Proceedings of the $15^{\text {th }}$ International Academic MindTrek Conference: Envisioning Future Media Environments (pp. 9-15). Tampere, Finland: ACM. https://doi.org/10.1145/2181037.2181040

DuVernet, A. M., \& Popp, E. (2014). Gamification of workplace practices. TIP: The Industrial-Organizational Psychologist, 52(1), 39-44.
Ergle, D. (2015). Fostering employee engagement through gamification: AirBaltic forecast tool. Management, 10(3), 219-234.

Gartner (2015). Gartner Hype Cycle. Retrieved from http://www.gartner.com/technology/research/methodologies/hype-cycle.jsp

Gimson, A. (2012). Game on for virtual work and play: Engaging learners' interest with online role-play. Development and Learning in Organizations, 27(1), 22-24. https://doi.org/10.1108/14777281311291259

Hair, J. F., \& Ringle, C. M. (2011). PLS-SEM; indeed a silver Bullet. Journal of Marketing Theory and Practice, 19(2), 139-151. https://doi.org/10.2753/MTP1069-6679190202

Harter, J., \& Adkins, A. (2015). What great managers do to engage employees. Retrieved from https://hbr.org/2015/04/what-great-managers-do-toengage-employees

Huatari, K., \& Hamari, J. (2012). Defining gamification - a service marketing perspective. In Proceedings of the $16^{\text {th }}$ International Academic MindTrek Conference (pp. 17-22), 03-05 October 2012. Tampere, Finland. https://doi.org/10.1145/2393132.2393137

Hughes, A., \& Mccoy, K. (2015). Planning, developing, implementing serious game. Training Industry Magazine - Fall, pp. 16-19.

Jensen, M. (2012). Engaging the learner: Gamification strives to keep the user's interest. $T+D$ Magazine, 66(1), 41-44. Retrieved from http:// td.org

Kapp, K. (2014). Gamification of learning. Retrieved from http://www.lynda.com/Higher-Education-tutorials/Gamification-Learning/173211-2.html

Kastner, N. (2013). Gamification: from the arcade to the bank. ABA Bank Marketing, 45(10), 20-23.

Kim, B. (2015). The Popularity of gamification in the mobile and social era. Library Technology Reports, 51(2), 5-9.

Kumar, H. \& Raghavendran, S. (2015). Gamification, the fine art: fostering creativity and employee engagement. Journal of Business Strategy, 36(6), 3-12. https://doi.org/10.1108/JBS-10-2014-0119

Ludviga, I. \& Kalvina, A. (2016). Exploring the relationships between job satisfaction, work engagement and loyalty of academic staff. International Journal of Social, Behavioural, Educational, Economic, Business and Industrial Engineering, 10(1), 99-105.

Markos, S. \& Sridevi, M. S. (2010). Employee engagement: The key to improving performance. International Journal of Business and Management, 5(12), 89-96.

Meister, J. (2015). Future of work: Using gamification for human resources. Retrieved from http://www.forbes.com

Mihalicz, D. (2018). Employee engagement - solutions that work. Retrieved from http://www.effectivemanagers.com/dwight-mihalicz/employee-engagement-solutions-that-work/

Mollick, E. R., \& Rothbard, N. (2014). Mandatory fun: Consent, gamification and the impact of games at work. Philadelphia: The Wharton School Research Paper Series.

Morgan, C. A. (2015). Employee satisfaction surveys: Measuring staff engagement. Retrieved from https://www. b2binternational.com/publications/employee-satisfaction/

Oakes, K. (2014). The evolution of the training profession. In E. Biech (Ed.), ASTD Handbook: The definitive reference for training \& development (pp. 40-56). Alexandria: ATD Press. 


\section{USE OF GAMIFICATION IN HUMAN RESOURCE MANAGEMENT: IMPACT ON ENGAGEMENT AND SATISFACTION}

Rich, B., Lepine, J., \& Crawford, E. (2010). Job engagement: antecedents and effect on job performance. Academy of Management Journal, 53(2), 617-635. https://doi.org/10.5465/amj.2010.51468988

Ringle, C. M., Wende, S., \& Becker, J.-M. (2014). SmartPLS. Hamburg: Smart-PLS.

Robbins, S. P., \& Coulter, M. (1999). Management (6 ed.). Prentice Hall.

Roberts, B. (2014). Gamification: Win, lose or draw?. HR Magazine, 59(5), 29-35.

Saran, C. (2013). A business case for gameplay at work. Computerweekly.com, 19, pp. 19-22.

Sarangi, S. \& Shan, S. (2015). Individuals, teams and organizations score with gamification. Human Resource Management International Digest, 23(4), 24-27. https://doi.org/10.1108/HRMID-05-2015-0074

Savitz, E. (2012). Let's play: To keep gen Y staffers, gamify their work. Forbes.

Schaufeli, W. B., Bakker, A. B., \& Salanova, M. (2006). The measurement of work engagement with a short questionnaire. Educational and Psychological Measurement, 66(4), 701-716.

https://doi.org/10.1177/0013164405282471
Seaborn, K., \& Fels, D. (2015). Gamification in theory and action: A survey. International Journal of HumanComputer Studies, 74, 14-31. https://doi.org/10.1016/j.ijhcs.2014.09.006

SHRM. (2014). Employee job satisfaction and engagement: Optimising organisational culture for success. SHRM.

Skinner, H., Sarpong, D., \& White, G. R. (2018). Meeting the needs of the millennials and Generation Z: gamification in tourism through geocaching. Journal of Tourism Futures, 4(1), 93-104. https://doi.org/10.1108/JTF-12-2017-0060

Smith, J. L., \& Meyerson, D. (2015). Strategic play. Wordzworth Publishing.

Werback, K. (2014). (Re)Defining gamification: A process approach. University of Pennsylvania. https://doi.org/10.1007/978-3-319-07127-5_23

Whyte, D. (2016). Training trends for 2016. Retrieved from www.trainingjournal.com

$\mathrm{Xu}, \mathrm{Y}$. (2011). Literature review on web Application Gamification and Analytics. CSDL Technical report 11-05.

Zichermann, G., \& Cunningham, C. (2011). Gamification by design. Canada: O’Reilly Media. 